\title{
GOVERNAMENTALIDADE E PRÁXIS EDUCACIONAL NA CONTEMPORANEIDADE
}

\author{
Avelino da Rosa Oliveira * \\ Kelin Valeirão ${ }^{* *}$
}

\begin{abstract}
RESUMO
$\mathrm{O}$ artigo visa discutir a práxis educacional na contemporaneidade, a partir do conceito de governamentalidade, desenvolvido por Michel Foucault. Inicialmente, apresenta-se a caracterização do conceito como ferramenta analítica para uma ontologia do presente. No segundo momento, estuda-se historicamente a escola moderna como "máquina de governamentalidade". Finalmente, trabalha-se a governamentalidade ligada à práxis educacional na atual sociedade de controle. Conclui-se que a práxis educacional na contemporaneidade atua como um dispositivo que funciona em sintonia com a forma de governamentalidade da sociedade de controle, contribuindo para capturar não mais corpos dóceis, mas flexíveis e ajustados às emergentes necessidades da sociedade.
\end{abstract}

Palavras-chave: Educação. Crise da escola. Práxis educacional. Governamentalidade. Sociedade de controle.

\begin{abstract}
Grounded on the conceptofgovernmentality, developed by MichelFoucault, the paper aims at discussing educational praxis in contemporaneity, First, the characterization of the concept is introduced as an analytical tool for an ontology of the present. After, modern school is historically studied as a "governmentality machine". Finally, governmentality is linked to
\end{abstract}

\footnotetext{
* Doutor em Filosofia pela Universidade Federal do Rio Grande do Sul (UFRGS). Professor Titular no Departamento de Fundamentos da Educação da Universidade Federal de Pelotas (UFPel). E-mail: avelino.oliveira@gmail.com

** Mestre em Educação pela Universidade Federal de Pelotas (UFPel). Professora do Departamento de Filosofia da UFPel. Doutorado em andamento no Programa de PósGraduação em Educação da Universidade Federal de Pelotas (UFPel). E-mail: kpaliosa@ hotmail.com
} 
educational praxis in the contemporary control society. It is concluded that educational praxis in contemporaneity operates as device that works in accordance with the governmentality forms of the control society, helping capture not anymore docile bodies but flexible ones, well adjusted to the emergent social needs.

Keywords: Education. School crisis. Educational praxis. Governmentality. Control society.

"Não sou um escritor, um filósofo nem uma grande figura da vida intelectual: sou um professor" (FOUCAULT, 2004, p. 294, grifo meu).

Perda das certezas, inconstância de metas, carência de perspectivas, emaranhado de dúvidas... crise. Crise de valores, crise do sujeito, crise de paradigmas. Por fim, adensando o infindável coro, nós, os educadores, lamentamos - crise da escola. E, de súbito, somos traga-dos pela voragem das dúvidas. Pois, em tempos assim, simultaneamente inquietantes e férteis, é preciso sempre, de novo, lançar-se à mesma aventura crítica que empreenderam, por exem-plo, Kant, Hegel, Adorno e Horkheimer, Nietzsche, Max Weber; aventura à qual corajosa-mente filiou-se Foucault, sob a forma de uma ontologia do presente.

Haverá, mesmo, uma crise da escola, um suposto desencaixe entre a escola e a socie-dade contemporâneas? Ou, quem sabe, não poderia essa nossa sensação de inadequação entre escola e sociedade esconder/ revelar novos ângulos de visão do problema? À luz dos cursos ministrados por Michel Foucault no Collège de France de 1970 a 1984, queremos enfrentar estas questões numa reflexão em três momentos. Inicialmente, buscamos configurar o conceito de governamentalidade e discutir sua associação com a ontologia do presente, estabelecendo-o, assim, como ferramenta analítica preponderante na compreensão da escola na contemporaneidade. A seguir, relacionamos a Modernidade à invenção da escola, passando rapida-mente por alguns dos autores que marcam esse período. Discutimos, ainda, a caracterização da escola moderna como "máquina de governamentalidade". Finalmente, no terceiro momento, trabalhamos a 
governamentalidade ligada à práxis educacional na contemporaneidade, visando indicar pistas que nos deem a entender as formas como, na sociedade de controle, a escola contribui para capturar não mais corpos dóceis, mas corpos flexíveis, ajustados às e-mergentes necessidades da sociedade. Deste modo, almejamos mostrar que, de certo modo, talvez não seja adequado falar-se em "crise da escola"; ou, em outras palavras, que não há, verdadeiramente, um desencaixe entre a escola e a sociedade contemporânea.

\section{Governamentalidade e ontologia do presente}

O termo governamentalidade, cunhado por Foucault, deriva da tradução da palavra francesa governamentalité. Na aula de $1^{\circ}$ de fevereiro de 1978, Foucault propõe três formas para sua compreensão:

Por esta palavra, "governamentalidade", entendo o conjunto constituído pelas instituições, os procedimentos, análises e reflexões, os cálculos e as táticas que permitem exercer essa forma bem específica, embora muito complexa, de poder que tem por objetivo principal a população, por principal forma de saber a economia política e por instrumento técnico essencial os dispositivos de segurança. Em segundo lugar, por "governamentalidade" entendo a tendência, a linha de força que, em todo o Ocidente, não parou de conduzir, e desde há muito, para a preeminência desse tipo de poder que podemos chamar de "governo" sobre todos os outros - soberania, disciplina - e que trouxe, por um lado, o desenvolvimento de toda uma série de aparelhos específicos de governo [e, por outro lado], o desenvolvimento de toda uma série de saberes. Enfim, por "governamentalidade", creio que se deveria enten-der o processo, ou antes, o resultado do processo pelo qual o Estado de justiça da Idade Média, que nos séculos XV e XVI se tornou o Estado administrativo, viu-se pouco a pouco "governamentalizado" (FOUCAULT, 2008, p. 143-144).

A governamentalidade constitui-se, portanto, em ferramenta de pesquisa, em lente que permite enxergar o modo como operamos dispositivos de seguridade, um campo estratégico de relações de poder (dispositivo 
poder-saber). Podemos entendê-la como a articulação entre a dimensão política e a dimensão ética, pois, até 1979, o conceito aparece como uma estratégia para governar os outros - processo de governamentalização do Estado - e nos anos 1980 apa-rece como uma estratégia para governar a si mesmo.

A problematização que orienta o diagnóstico da filosofia de Foucault como ontologia do presente funda-se no conceito de governamentalidade. O neologismo foucaultiano surge, pois, como estratégia de poder voltada para governar, conduzir as condutas dos outros e a sua própria conduta. A governamentalidade é uma instrumentação voltada para a gestão dos indivíduos. No entanto, as individualidades têm como referência a noção de população. Trata-se de salvar a população no sentido mundano do termo, assegurá-la contra os perigos internos e externos, ordená-la, garantir seu bem-estar e seu desempenho, fazendo crescerem e multiplicarem-se as forças sociais.

A governamentalidade irá se desenvolver como uma razão de Estado e terá como princípio não o fortalecimento do monarca, mas o fortalecimento do próprio Estado. Para Foucault, justamente no momento histórico em que o Estado começa a praticar seus maiores massacres, ele também começa a se preocupar com a saúde física e mental dos indivíduos. A arte de governar implica, pois, um saber que não é meramente a justiça, mas, sim, uma ciência de governo, um conhecimento sobre as forças do Estado, suas capacidades e os meios de desenvolvê-las.

Um ângulo de abordagem que pode tornar mais transparente o problema é a referência ao conceito de "governo" e sua diferenciação em relação ao "governamento". Para Foucault, governar "é estruturar o eventual campo de ação dos outros". As relações de poder não são da ordem "da violência e da luta, nem do lado do contrato e da aliança voluntária (que não podem ser mais do que instrumentos); porém, do lado deste modo de ação singular - nem guerreiro nem jurídico - que é o governo" (FOUCAULT, 1995, p. 244). Governo, entretanto, não é o mesmo que governamento. Sugerimos tomar o caminho de diferenciação proposto por Veiga-Neto (2005). Segundo o autor, Foucault faz uso de dois vocábulos que, na língua francesa, apresentam significados distintos, mas, que na língua portuguesa, dentro de cânones rígidos, teriam que ser ambos traduzidos por "governo". 
Assim, o mesmo termo teria que assumir pelo menos dois significados: ora deveria ser entendido em associação à instituição do Estado (Governo do Município, Governo do Estado, Governo da República, dentre outros tantos); ora deveria ser tomado como ação de governar (uma cidade, uma escola, uma família, uma criança, dentre outras tantas possibilidades).

Este segundo sentido - ação de governar - compreende práticas múltiplas, pois “o que está grafado como 'práticas de governo' não são ações assumidas ou executadas por um staff que ocupa uma posição central no Estado, mas são ações distribuídas microscopicamente pelo tecido social" (VEIGA-NETO, 2005, p. 21). Portanto, parece ser mais adequado neste caso falar-se em práticas de "governamento", para designar as práticas de governo que não estão necessariamente vinculadas à instituição estatal. Em contrapartida, mantém-se o termo "governo", de forma geral, em referência às instituições centralizadoras de poder (como, por exemplo, o Estado).

Estabelecida esta distinção, pode-se perceber mais facilmente o movimento histórico da escola em articulação com a sociedade. Enquanto na Modernidade desenvolve-se um aparato estratégico em torno da vigilância e da docilidade do corpo do indivíduo, na contemporaneidade busca-se uma nova estratégia voltada para o controle do cérebro, a fim de garantir um sujeito flexível, que seja empresário de si. Neste sentido, pode-se apontar o deslocamento de uma sociedade disciplinar para uma sociedade de controle.

Naquele primeiro cenário, a escola moderna constituiu-se em eficiente maquinaria de governamento dos corpos infantis, apresentando uma práxis educacional bastante distinta da que encontramos hoje. Assim, sugerimos um retorno temporal em busca das raízes da escola moderna, com suas estratégias específicas, em sintonia com a sociedade disciplinar.

\section{A modernidade e a invenção da escola}

$\mathrm{Na}$ contemporaneidade, parece haver consenso quanto à importância da educação e da disciplina. O que é, entretanto, uma boa educação? E o que é ser disciplinado? Na escola e nos mais variados discursos estão presentes questões relativas à indisciplina, apontada por 
grande parte dos professores como uma das causas do baixo rendimento dos alunos. É notório que esse tema ocupa lugar de destaque na lista de reclamações feitas pelas escolas às famílias dos educandos, e vice-versa. De tal contexto, eclodem questões incontornáveis: educar é sinônimo de disciplinar? É seu pressuposto? Como se estabeleceu a relação de inseparabilidade entre educação e disciplinamento?

A escola, grande máquina de vigilância da modernidade, resulta de um longo processo histórico que a coloca como o lugar privilegiado, exclusivo e legitimado de saber. Local onde, através do ato de educar, os sujeitos são tirados do estado de "selvageria". Não se trata, aqui, de concordar ou divergir da escola ou da forma como ela está posta, mas de analisar a escola enquanto instituição disciplinar, através da diferenciação entre exercício de violência e relações de poder, principalmente quando surgem, nos séculos XVII e XVIII, as chamadas "disciplinas" que tinham por objetivo tornar a criança um corpo dócil e útil ao corpo social, e a forma como estas disciplinas vêm sendo utilizadas no campo da Educação.

A escola, enquanto máquina de vigilância e disciplinamento, constitui-se em espaço de governamento da alma dos sujeitos, operando a partir de sua subjetividade, fazendo uso do poder que a sustenta. As teorias psicológicas, fortemente presentes na escola, administram a alma de forma aparentemente livre, mas não isenta das mais profundas relações de poder. Desta forma, a escola foi inventada para disciplinar e exercer governamento sobre os sujeitos modernos, dispensando o uso da violência, valendo-se de métodos sutis de persuasão que agem de forma indireta sobre suas escolhas, seus desejos e sua conduta, deixando-os "livres para escolher", mesmo que constantemente envolvidos por normas que os aprisionam à própria consciência. Portanto,

a escola moderna é o locus em que se dá de forma mais coesa, mais profunda e mais duradoura a conexão entre poder e saber... funcionando, assim, como uma máquina de governamentalização que consegue ser mais poderosa e ampla do que a prisão, o manicômio, o quartel, o hospital (VEIGA-NETO, 2001, p.109).

A construção da subjetividade operada pela escola é um aspecto evidente, dado que a identidade se constitui a partir dos processos 
culturais. Para Veiga-Neto (2006, p. 34) "a partir do século XVII a escola constituiu-se como a mais eficiente maquinaria encarregada de fabri-car as subjetividades". Na contemporaneidade, entretanto,

boa parte da subjetividade operada na e pela escola... ou se deslocou para o espaço social mais amplo ou, mesmo ainda ocorrendo no espaço escolar, deixou de contar com aquele tipo de poder e aquelas práticas (como tecnologias) para a fabricação de sujeitos". Assim, nos tempos em que vivemos, além da escola não ser detentora da produção da identidade das crianças, também não é a instituição mais importante. Cada vez mais, os artefatos midiáticos estão subjetivando, regulando e exercendo o governamento. Importa ainda salientar que "são as 'práticas' concebidas ao mesmo tempo como modo de agir e de pensar que dão a chave de inteligibilidade para a constituição correlativa do sujeito e do objeto (FOUCAULT, 2004, p. 238).

Entre essas práticas, as que envolvem relações de poder, principalmente do poder disciplinar e das estratégias de controle, são cruciais para compreender como nos tornamos sujeitos.

Ao analisar a escola numa perspectiva foucaultiana, é mister salientar a diferenciação entre o exercício de violência e as relações de poder, além de atentar para o fato de que tal distinção é qualitativa e não quantitativa. Uma relação de poder diferencia-se do exercício de violência por usar saberes, enquanto a segunda usa a agressão física, econômica etc.

Uma relação de violência age sobre um corpo, sobre as coisas; ela força, ela submete, ela quebra, ela destrói; ela fecha todas as possibilidades; não tem, portanto, junto de si, outro pólo senão aquele da passividade; e, se encontra uma resistência, a única escolha é tentar reduzi-la. Uma relação de poder, ao contrário, se articula sobre dois elementos que lhe são indispensáveis por ser exatamente uma relação de poder: que "o outro" (aquele sobre o qual ela se exerce) seja inteiramente reconhecido e mantido até o fim como sujeito de ação; e que se abra, diante da relação de poder, todo um campo de respostas; reações, efeitos, invenções possíveis (FOUCAULT, 1995, p. 243). 
Para Veiga-Neto (2006, p. 29) "o poder disciplinar faz de uma punição uma ação racional, calculada e, por isso, econômica, a violência faz de uma punição uma ação cuja racionalidade é de outra ordem e que, não raro, beira a irracionalidade." As instituições escolares, enquanto práticas pedagógicas, são da ordem da disciplina, do poder disciplinar, funcionando como "técnicas que constituem uma 'profunda' estratégia para dividir as pessoas em grupos disciplinados, individualizados, controláveis" (RAJCHMAN, 1987, p. 63). Desta forma, a escola age como dispositivo para dizer o que pode ser dito, feito ou pensado. Segundo Foucault, resulta também das disposições disciplinares que "o sujeito é dividido no seu interior e em relação aos outros" (FOUCAULT, 1995, p. 231). Nesta perspectiva, o processo de disciplinarização, transmitido pelas escolas, busca assegurar a ordenação das multiplicidades humanas.

Foucault, no seu estudo genealógico, propõe a articulação entre o poder e o saber, onde as disciplinas estão ligadas aos regimes de verdade, ou seja, as disciplinas "não apenas engendram determinadas maneiras de perceber o mundo e de atuar sobre ele, como, também, separam o que é (considerado) verdadeiro daquilo que não o é" (VEIGA-NETO, 2006, p. 26). Enfim, não é demais recordar que o efeito do poder disciplinar não é a apropriação violenta de um corpo para dele extrair energia, afeto, submissão e trabalho, mas o adestramento sutil, tornando-o corpo dócil e útil para o corpo social.

Segundo Comenius, autor de um dos tratados educacionais que mais solidamente alicerça a Modernidade, "a todos aqueles que nasceram homens é necessária a educação, porque é necessário que sejam homens, não animais ferozes, nem animais brutos, nem troncos inertes" (COMÉNIO, 1957, p. 125). A visão de educação sustentada pela escola moderna - ensinar tudo a todos - funda-se na compreensão de que todo o ser humano é naturalmente capaz de ser educado, por isso a considera obrigatória. Assim, a perspectiva comeniana de educação não aceita que alguém não passe pelo processo de escolarização. Tendo por base a educabilidade humana, faz-se necessário instituir pedagogias corretivas que deem conta daqueles "ineptos" que não se ajustam ao padrão de normalidade prefigurado. 
As pedagogias corretivas partem do princípio de que toda criança é um selvagem que precisa ser corrigido e docilizado, sendo o bom selvagem aquele que está apto a aprender, levando em conta sua natureza educável. A correção, enquanto um dos objetivos das pedagogias disciplinares, já não ocorre mais através da violência, torna-se indireta, deslocandose para a organização do meio, já que prega uma ação educativa ativa e criativa, respeitando o desenvolvimento infantil, enfim, operando a partir da subjetividade. A regulação e o controle exercidos por essa pedagogia tornam clara a tentativa de homogeneização das classes escola-res, uma vez que através do próprio autogoverno os sujeitos passam a buscar o modelo de normalidade que devem atingir.

Locke, filósofo precursor do empirismo, viveu boa parte da sua vida durante o século XVII, período em que ocorreram profundas mudanças nas relações sociais e nas mentalidades, especialmente na Inglaterra. Em 1693, publica a obra Some thoughts concerning education (Alguns pensamentos acerca da educação), em que a questão da disciplina é vastamente desenvolvida, visando a formação de boas maneiras para que, enquanto perdurar o período de transição da sociedade feudal à burguesa, a educação lance os alicerces de sustentação do no-vo momento a ser instaurado.

Mas Locke não é um entusiasta da escola como instrumento disciplinar; pelo contrário, está convicto "de que o homem que é capaz de ter em casa um tutor pode oferecer ao filho uma conduta mais polida... com maior proficiência do que qualquer escola" (Locke, 2001, p. 170). Tal posição, no entanto, não se deve a qualquer julgamento de que os professores sejam incapazes de instruir os filhos. Para ele, as crianças necessitam de atenção constante e indivi-dual o que, segundo o filósofo, se torna inviável devido ao grande número de alunos na esco-la. Ademais, argumenta que na escola a criança encontra ambiente e companhias que a afastam do caminho desejado.

Kant, pensador moderno do final do século XVIII, afirmava que "a falta de disciplina é um mal pior que a falta de cultura, pois esta pode ser remediada mais tarde, ao passo que não se pode abolir o estado selvagem e corrigir um defeito de disciplina" (KANT, 2002, p. 16). E ainda sobre o disciplinamento, mais especificamente sobre a subjugação do corpo, declara que "as crianças são mandadas cedo à escola, não para que aí 
aprendam alguma coisa, mas para que aí se acostumem a ficar sentadas tranqüilamente e a obedecer pontualmente àquilo que lhes é mandado" (KANT, 2002, p. 13). Deste modo, o filósofo evidencia o objetivo da escola moderna: a disciplina. Ao associar a disciplina à escola, Kant marca de forma importante o papel que o tempo e o espaço ocupam nesse processo. E talvez tenha sido ele o primeiro a indicar o compromisso da escola moderna com o disciplinamento dos corpos infantis.

A escola, em sua constante busca pelo enquadramento dos sujeitos, normatiza o tempo, produzindo sujeitos autocontrolados. Ao normatizar o tempo, a escola passa a exigir que todos internalizem, apreendam esse tempo que serve como medida comum para todos, determinando a aprendizagem e excluindo aqueles que não se enquadram nos tempos convencionados. Responsabilizar os sujeitos pela sua adequação ao tempo escolar, pelo ritmo de sua aprendizagem, caracteriza-se como uma perversa estratégia da escola moderna para determinar aqueles que podem ou não ocupar o espaço escolar.

Foucault constata que a articulação poder-saber nos séculos XVII e XVIII permite um controle minucioso sobre os corpos dos indivíduos, com o intuito de produzir corpos dóceis e úteis para o corpo social. Nesta perspectiva, a escola passa a ser um ambiente de dominação e controle, uma estratégia para documentar individualidades. É sabido que anteriormente a este período já existiam diversos processos disciplinares, porém, nesta fase específica, as disciplinas atuaram como verdadeiras estratégias de dominação:

O momento histórico das disciplinas é o momento em que nasce uma arte do corpo humano, que visa não unicamente o aumento de suas habilidades, nem tampouco aprofundar sua sujeição, mas a formação de uma relação que no mesmo mecanismo o torna tanto mais obediente quanto é mais útil, e inversamente (FOUCAULT, 1987, p. 119).

Instaura-se uma anatomia política do corpo, uma análise minuciosa que estuda as for-mas, as estruturas e as relações deste corpo-objeto, atuando como mecanismo de poder. Isto, porém, não ocorre de maneira inesperada. Há muito tempo, esta anatomia política do corpo encontra-se 
em funcionamento nas mais diversas instituições disciplinares como, por exemplo, nas escolas militares, nos conventos, nos asilos etc.

Não se trata de fazer aqui a história das diversas instituições disciplinares, no que podem ter cada uma de singular. Mas de localizar apenas numa série de exemplos algumas das técnicas essenciais que, de uma a outra, se generalizaram mais facilmente. Técnicas sempre minuciosas, muitas vezes íntimas, mas que têm sua importância: porque definem um certo modo de investimento político e detalhado do corpo, uma nova "microfísica do poder" (FOUCAULT, 1987, p. 120).

Ao investigar minuciosamente os regulamentos das instituições disciplinares, Foucault atenta para o controle das minúcias, o que leva a um complexo conjunto de informações e rela-ções de poder-saber que, sem dúvida, são constitutivos do homem moderno. A escola faz parte de uma rede produtiva que age sobre o corpo social, não somente enquanto poder re-pressivo, mas principalmente como um dispositivo de produção de subjetividade que tem a ver com o contexto disciplinar tanto na sala de aula como para além dela, afetando o processo de constituição do próprio sujeito.

se o poder só tivesse a função de reprimir, se agisse apenas por meio da censura, da exclusão, do impedimento, do recalcamento, à maneira de um grande super-ego, se apenas se exercesse de um modo negativo, ele seria muito frágil. Se ele é forte, é porque produz efeitos positivos a nível do desejo - como se começa a conhecer - e também a nível do saber (FOUCAULT, 1982, p. 148).

Dando mais um passo na compreensão do poder disciplinar, convém mencionar o pa-nopticon, idealizado por Jeremy Bentham no final do século XVIII. O utilitarista inglês pro-põe um centro penitenciário ideal, desenha o projeto arquitetônico de sua construção e dedica-se a estudar todos os detalhes de seu funcionamento. Trata-se, em suma, de um artefato de disciplinarização que ultrapassa, de longe, a especificidade de uma penitenciária. $\mathrm{O}$ conceito expresso no desenho permite a um vigilante observar todos os prisioneiros sem que estes pos-sam saber se estão ou não 
sendo observados. De modo amplo, trata-se de uma torre de obser-vação localizada no pátio central de uma prisão, manicômio, escola, hospital ou fábrica. A-quele que estivesse sobre esta torre poderia observar todos os presos da cadeia (ou os funcio-nários, loucos, estudantes, etc.), tendo-os sob seu controle.

O princípio é: na periferia, uma construção em anel; no centro, uma torre; esta possui grandes janelas que se abrem para a parte interior do anel. A construção periférica é dividida em celas, cada uma ocupando toda a largura da construção. Estas celas têm duas janelas: uma abrindo-se para o interior, correspondendo 'as janelas da torre, outra, dando para o exterior, permite que a luz atravesse a cela de um lado a outro (FOUCAULT, 1982, p. 210).

Bentham busca uma administração disciplinar racional e acaba por criar uma detalhada tecnologia da vigilância, onde os indivíduos são mantidos sob um olhar permanente. Segundo Foucault, bastaria colocar um vigia na torre e em cada cela trancar um indivíduo (um aluno, um delinquente, um louco...) para que o panopticon pudesse substituir as masmorras. Trans-pondo-se tais técnicas para a instituição escolar, significa registrar, observar e anotar tudo sobre a vida escolar dos educandos, através de mecanismos específicos, como as avaliações individuais. Desta forma, não é preciso obrigar o aluno a ser aplicado, pois ele sabe que está sendo vigiado. A disciplina, então, surge como uma estratégia para distribuir os indivíduos no espaço, mas para isto é crucial ater-se a algumas técnicas, como a clausura, o quadriculamento, as localizações funcionais, a fila etc.

Foucault, ao se referir à disciplinarização através da estrutura arquitetônica, dirá que "cada aluno devia dispor de uma cela envidraçada onde ele podia ser visto durante a noite sem ter nenhum contato com seus colegas, nem mesmo com os empregados" (FOUCAULT, 1982, p. 210). Porém, somente a clausura não seria suficiente para os aparelhos ou instituições dis-ciplinares. O quadriculamento surge então da busca de poder vigiar o comportamento de cada indivíduo, saindo da análise coletiva, pluralista. O importante seria documentar individualida-des. Nesta perspectiva, é preciso que cada indivíduo ocupe um lugar e que cada lugar seja ocupado por um indivíduo, evitando-se as divisões em grupo. 
Importa estabelecer as presenças e as ausências, saber onde e como encontrar os indivíduos, instaurar as comunicações úteis, interromper as outras, poder a cada instante vigiar o comportamento de cada um, apreciá-lo, sancioná-lo, medir as qualidade ou os méritos. Procedimento, portanto, para conhecer, dominar e utilizar (FOUCAULT, 1987, p. 123).

Não obstante, era necessário não somente vigiar e conter as comunicações perigosas. A escola, enquanto aparelho disciplinador, precisava se constituir num espaço útil, pois o capitalismo só poderia ser garantido à custa da inserção controlada dos corpos no aparelho de produção e por meio de um ajustamento dos fenômenos de população aos processos econômi-cos. Portanto, fez-se necessário uma vigilância individual e geral, atentando para o lugar que cada indivíduo ocupa. A disciplina, assim, pode ser compreendida como "arte de dispor em fila, e da técnica para a transformação dos arranjos. Ela individualiza os corpos por uma loca-lização que não os implanta, mas os distribui e os faz circular numa rede de relações" (FOUCAULT, 1987, p. 125).

No século XVIII, as ordenações por fileiras começam a dividir o corpo discente de forma a organizar a escola em arranjos, surgindo as filas para entrar e sair da sala, filas no corredor, no pátio, por séries, por idade etc. Segundo Foucault, é este conjunto de alinhamen-tos, onde os alunos ora ocupam uma fila, ora outra, que marca as hierarquias do saber e do poder na instituição escola.

A Modernidade instituiu uma nova prática que não é a violência, pois a ação violenta exige uma guarda constante, enquanto aquele que é persuadido passa a exercer a ação sobre si mesmo. Para isso, é preciso que o sujeito habitue-se a manter vigilância sobre si próprio. Antes, porém, alguém precisa vigiá-lo: a escola. Nesta lógica, a escola atua como uma potente maquinaria na busca constante do enquadramento dos sujeitos, podendo ser associada a uma forma específica de conduzir a conduta das crianças. Dito de outro modo, a escola pode ser compreendida enquanto uma instituição a serviço da sociedade, como uma maquinaria encarregada de disciplinar os corpos infantis. Assim, nesse momento histórico, o chamado Estado Administrativo ou Estado de Polícia tinha como estratégia a regulamentação por meio de dis-positivos disciplinares que buscavam a normatização dos corpos. 


\section{Governamentalidade e práxis educacional hoje: alguns deslocamentos}

A práxis educacional na contemporaneidade constitui uma nova racionalidade, uma nova maneira de conduzir a conduta das pessoas. Não se trata, entretanto, de algo absolutamente apartado da práxis educacional anterior, típica da sociedade disciplinar. Não se pode compreender tais passagens como substituições compartimentalizadas de uma sociedade de soberania para uma sociedade de disciplina e, após, para uma sociedade de governo. Para Foucault, estamos diante de um triângulo: soberania, disciplina e gestão governamental.

Perceber com maior nitidez o presente em que vivemos exige a percepção do deslocamento da sociedade disciplinar para a sociedade de controle, assim como o estudo da forma como este movimento vincula-se não somente a uma maneira específica de conduzir a conduta das pessoas, mas também à chamada "crise da educação". Este deslocamento, apontado inicialmente por Foucault, é desenvolvido por Gilles Deleuze. No artigo Post-Scriptum Sobre as sociedades de controle, Deleuze apresenta o histórico, a lógica e o programa desta transição da sociedade disciplinar, situada por Foucault nos séculos XVIII e XIX, atingindo seu ápice no início do século XX, para a sociedade de controle. Neste ensaio, Deleuze aposta numa filosofia política centrada na análise do capitalismo, podendo situarse seu estudo como uma analítica histórica das revoluções do capitalismo que, de certa forma, inspira-se na análise proposta por Karl Marx.

Deleuze argumenta que, no âmbito do capitalismo, é possível perceber diferenciações entre a sociedade disciplinar e a sociedade de controle. Nesta estratégia de busca de mutações, o dinheiro constitui-se num dos indicadores a serem observados. Enquanto a sociedade disciplinar faz referência à "moeda cunhada a ouro" como medida padrão do valor, a sociedade de controle "remete a trocas flutuantes, modulações que fazem intervir como cifra uma percenta-gem de diferentes amostras de moeda". Assim, "o homem da disciplina era um produtor descontínuo de energia, mas o homem do controle é antes ondulatório, funcionando em órbita, num feixe contínuo" (DELEUZE, 1996, p. 222-223). Outro indicador de mutações sociais refere-se aos tipos específicos de máquinas utilizadas, pois, segundo o autor, elas expressam as formas sociais onde surgem, assim como, sua utilidade. 
As antigas sociedades de soberania manejavam máquinas simples, alavancas, roldanas, relógios; mas as sociedades disciplinares recentes tinham por equipamento máquinas energéticas, com o perigo passivo da entropia e o perigo ativo da sabotagem; as sociedades de controle operam por máquinas de uma terceira espécie, máquinas de informática e computadores, cujo perigo passivo é a interferência, e, o ativo, a pirataria e a introdução de vírus. Não é uma evolução tecnológica sem ser, mais profundamente, uma mutação do capitalismo (DELEUZE, 1996, p. 223).

Embora as concepções até aqui apresentadas sejam suficientes para o nosso propósito de investigar os mecanismos de governamento nas sociedades contemporâneas, se desejamos tomar um autor mais recente, é possível recorrer, por exemplo, a Mauricio Lazzarato que observa que a passagem da sociedade disciplinar para a sociedade de controle não está associada somente às transformações do sistema capitalista, mas também à potência de multiplicidades.

Nas sociedades de controle, a finalidade não é mais auferir antecipadamente os lucros, como nos regimes de soberania, nem combinar e aumentar a potência das forças, como nas sociedades disciplinares. Nas sociedades de controle, a questão é efetuar os mundos. A valorização capitalista fica subordinada, doravante, a essa condição (LAZZARATO, 2006, p. 99).

Nas sociedades de controle há uma multiplicação da "oferta de mundos", claramente perceptível através dos meios de consumo, de informação, de lazer etc. Esta oferta é constituída "pelos agenciamentos de enunciação, pelos regimes de signos em que a expressão recebe o nome de publicidade e em que a expressão constitui uma solicitação, um comando". Estes comandos são "formas de avaliação, de julgamento, repertório de crenças trazido para o mun-do, a respeito de si mesmo e dos outros" (LAZZARATO, 2006, p. 100), tratando-se de mundos vazios de singularidades. Assim, sendo as sociedades de controle nulas em singularidades, temos a sensação de que, sendo tudo possível, nada mais há a ser feito; e esta desagradável sensação de impotência acaba abarcando 
as diferentes instituições da sociedade, dentre elas a escola, causando uma sensação de crise entre o esperado e o alcançado. Deste modo, a chamada "crise da educação" está ligada à crise disciplinar, ou seja, o deslocamento da sociedade disciplinar para a sociedade de controle está na raiz de tais transformações. Desta forma, a alegada crise atual da educação escolar "pode ser compreendida como parte da agudização de uma crise bem mais geral, a saber, uma crise da espacialização moderna" e "é também uma crise da soberania do Estado-nação" (VEIGA-NETO, 2006, p. 34).

A educação não consegue eximir-se de culpa pela pretensa crise. Apesar dos esforços dos profissionais da área em tentar dividir o delito com os demais trabalhadores sociais, "ela é vista como ocupando uma posição central e desempenhando a função de causa da crise" (VEIGA-NETO, 2000a, p. 45), uma vez que a escola está diretamente ligada à perspectiva de futuro, tanto no que diz respeito ao futuro dos cidadãos que passam anos sob sua responsabilidade, quanto no que diz respeito à manutenção da ordem e da segurança na sociedade.

A escola atua como instituição disciplinadora a serviço da sociedade, no plano individual (sujeito) e coletivo (ordem social). A sensação de crise que experimentamos cotidiana-mente é fruto de uma aparência de desencaixe entre a escola e a sociedade atual, uma vez que o mundo globalizado anda num ritmo acelerado enquanto a escola parece manter-se no com-passo anterior. Essa sensação de crise, no entanto, não é nova. Configura-se como sensação permanente e está presente desde os primeiros tratados educacionais da própria Modernidade. Comenius, na sua conhecida Didática magna, já fazia uma tentativa de reverter a situação das escolas do século XVII. Assim, podemos associar a própria invenção da escola moderna a um momento de crise.

A escola, na contemporaneidade, está envolvida, isto sim, num processo de mudança de ênfase nos modos de subjetivação. Enquanto a escola moderna é identificada com a sociedade disciplinar, com todas as suas técnicas e procedimentos de vigilância, sanção normaliza-dora e exame, a fim de alcançar corpos dóceis e úteis ao corpo social, a escola que chamamos de pós-moderna está associada à sociedade de controle que se agencia por intermédio de mecanismos de controle, a fim de capturar corpos flexíveis. Este é, pois, o núcleo do câmbio de ênfase: enquanto a 
sociedade disciplinar conta com os procedimentos disciplinares, a sociedade de controle confia em procedimentos de controle que, "assentados na instantaneidade e reversibilidade dos fluxos informacionais nas redes eletrônico-digitais rizomáticas, investem, muito particularmente, sobre os espaços institucionais-disciplinares" (VEIGA-NETO; MORAES, 2008, p. 344). Assim, "a ênfase na estrutura hierárquica, centralizada, estável e arborescente da disciplina escolar - seja no eixo do corpo, seja no eixo dos saberes - desloca-se, agora, em favor de práticas escolares mais flexíveis, descentralizadas, cambiantes e rizomáticas" (VEIGA-NETO; MORAES, 2008, p. 344). Deste modo, os processos de subjetivação operados pela escola passam das formas únicas e determinadas para a multiplicidade difusa, ou seja, vão das formas centralizadas e rígidas para formas aleatórias e flexíveis.

Há, portanto, um jogo entre o arcaico e o novo, na sociedade, em geral, e na escola, em particular. A escola pensa e age apresentando uma nova forma de conduzir a conduta dos corpos infantis. E esta nova governamentalidade, encontrada igualmente na sociedade neoliberal, traz duas características marcantes: a primeira, uma bricolagem de informações, fruto do chamado mundo globalizado; a segunda, a busca pelo conservadorismo, denunciada pela avidez por manter a disciplina. A alusão à bricolagem de informações remete, de um lado, ao processo de globalização, com suas múltiplas ofertas de mundo; de outro lado, à nossa suposta "liberdade de escolha" dentre as possibilidades que foram instituídas e concebidas por outrem. Assim, esta nova tecnologia de governamento, presente na sociedade atual, faz com que a escola, enquanto máquina de governamentalidade, esteja cada vez mais preocupada em formar sujeitos autônomos, sujeitos que saibam conduzir a si mesmos ou, como já foi dito, sujeitos que sejam empresários de si. Em suma, a escola atua como uma maquinaria encarregada de preparar competências que orientem os futuros sujeitos-clientes a atuarem num mundo marcado pelo mercado e pela competição. E o mundo globalizado é entendido como "nova desordem mundial", uma vez que "ninguém parece estar no controle agora" (BAUMAN, 1999, p. 66). Todavia, a escola não abandona os mecanismos de controle. Ao contrário, a ins-tituição está cada vez mais se deslocando de uma lógica disciplinar para uma lógica de contro-le; e 
o controle permanente "funciona como um agenciamento coletivo cujos resultados, num futuro próximo, podem ser sombrios" (VEIGA-NETO, 2000, p. 209).

Quanto à busca pelo conservadorismo, conforme já bem salientado, a escola procura manter a disciplina tanto no plano individual (disciplinar os corpos para viver em sociedade) quanto coletivo (manter a ordem social). Assim, em diferentes momentos históricos, a escola, enquanto instituição a serviço da sociedade, recorreu a diferentes estratégias para manter a disciplina. Se, na sociedade moderna, vemos a escola em busca de estados de docilidade du-radoura, hoje ela se coloca não mais centrada na docilidade, mas sim na flexibilidade do cor-po. Neste sentido, a solidez da sociedade disciplinar moderna que buscava a estabilidade atra-vés da disciplina, da docilidade dos corpos, está dando lugar à liquidez pósmoderna, de modo que a escola está cada vez menos preocupada com a fabricação de corpos dóceis e cada vez mais ocupada com a fabricação de corpos flexíveis, corpos que saibam jogar o jogo do livre-mercado.

Concluindo esse esforço de tomar o neologismo foucaultiano da governamentalidade e de fazê-lo incidir, como ferramenta de análise, sobre a práxis educacional da contemporaneidade, queremos crer que alguma produtividade foi daí extraída. Acreditamos ter mostrado que, pelo menos, é preciso colocar sob suspeita e refletir mais detidamente sobre as alegações de "crise da escola". A práxis educacional hoje permanece como dispositivo em plena sintonia com uma determinada forma de governamentalidade. Assim, ao discutir a articulação entre governamentalidade e práxis educacional na contemporaneidade, percebemos que esta última se coloca dentro de uma ordem discursiva que dá sustentação à governamentalidade da sociedade de controle, assim como é por ela sustentada.

\section{Referências}

BAUMAN, Zygmunt. Globalização: as conseqüências humanas. Rio de Janeiro: Jorge Zahar, 1999.

COMÉNIO, Jean Amós. Didactica magna. Praga, 1957.

DELEUZE, Gilles. Post-scriptum sobre as sociedades de controle. In: . Conversações: 1972-1990. Rio de Janeiro: Editora 34, 1992, p. 
219-226.

FOUCAULT, Michel. Microfísica do poder. Tradução e organização de Roberto Machado. Rio de Janeiro: Graal, 1982.

. Vigiar e punir. Petrópolis: Vozes, 1987.

. O sujeito e o poder. In: DREYFUS, Hubert; RABINOW, Paul. Michel Foucault. Uma trajetória filosófica: para além do estruturalismo e da hermenêutica. Rio de Janeiro: Forense Universitária, 1995, p. 231-249.

. Ditos \& escritos: Ética, Sexualidade, Política. v. 5. Rio de Janeiro: Forense Universitária, 2004, p. 234-239.

. Segurança, território, população. Tradução de Eduardo Brandão. São Paulo: Martins Fontes, 2008.

KANT, Immanuel. Resposta à pergunta: que é o iluminismo? In: A paz perpétua e outros opúsculos. Lisboa: Edições 70, 1990.

. Sobre a pedagogia. Piracicaba: Editora UNIMEP, 2002.

LAZZARATO, Mauricio. As revoluções do capitalismo. Rio de Janeiro: Civilização Brasileira, 2006.

LOCKE, John. Alguns pensamentos acerca da educação. Cadernos de Educação, Pelotas, n.13, ago./dez. 1999; até n. 23, jul./dez. 2004.

RAJCHMAN, John. Foucault: A liberdade da filosofia. Rio de Janeiro: Zahar, 1987.

VEIGA-NETO, Alfredo. Educação e governamentalidade neoliberal: novos dispositivos, novas subjetividades. In: Retratos de Foucault. Rio de Janeiro: NAU Editora, 2000, p. 179-217.

- Michel Foucault e os estudos culturais. In: COSTA, Marisa Vorraber (Org.). Estudos culturais em educação: mídia, arquitetura, brinquedo, biologia, literatura, cinema... Porto Alegre: Universidade, 2000a, p. 37-69.

. Incluir para excluir. In: LARROSA, Jorge; SKLIAR Carlos. Habitantes de Babel: politicas e poéticas da diferença. Belo Horizonte: Autêntica, 2001, p. 105- 118.

. Pensar a escola como uma instituição que pelo menos garanta a manutenção das conquistas fundamentais da Modernidade. In: COSTA, 
Marisa Vorraber (Org.). A escola tem futuro? Porto Alegre: DP\&A, 2003, p. 103-126.

. Coisas de governo... In: . Imagens de Foucault e Deleuze: ressonâncias nietzschianas. Rio de Janeiro: DP\&A, 2005, p. 13-34. . Dominação, violência, poder e educação escolar em tempos de Império. In: . Figuras de Foucault. Belo Horizonte: Autêntica, 2006, p. 13-43.

. Crise da Modernidade e inovações curriculares: da disciplina para o controle. In: PERES, Eliane et al. (Org.). Trajetórias e processos de ensinar e aprender: sujeitos, currículos e culturas. Porto Alegre: EDIPUCRS, 2008. p. 35-58.

; MORAES, Antônio Luiz de. Disciplina e controle na escola: do aluno dócil ao aluno flexível. Resumos do IV Colóquio Luso-Brasileiro sobre Questões Curriculares. Florianópolis: UFSC, 2008. p. 343-354.

Data de registro:08/10/2011

Data de aceite:02/05/2012 